\title{
Review
}

\section{A Review of Research on Dropwise Condensation Heat Transfer}

\author{
Xuechao Hu, Qiujie Yi *, Xiangqiang Kong (D) and Jianwei Wang \\ College of Mechanical and Electronic Engineering, Shandong University of Science and Technology, \\ Qingdao 266590, China; 201883050117@sdust.edu.cn (X.H.); xqkong@sdust.edu.cn (X.K.); \\ skd993920@sdust.edu.cn (J.W.) \\ * Correspondence: yiqiujie@sdust.edu.cn
}

\section{check for}

updates

Citation: Hu, X.; Yi, Q.; Kong, X.; Wang, J. A Review of Research on Dropwise Condensation Heat Transfer. Appl. Sci. 2021, 11, 1553. https://doi.org/10.3390/app 11041553

Academic Editor: Andrea Frazzica Received: 12 December 2020

Accepted: 6 February 2021

Published: 9 February 2021

Publisher's Note: MDPI stays neutral with regard to jurisdictional claims in published maps and institutional affiliations.

Copyright: (c) 2021 by the authors. Licensee MDPI, Basel, Switzerland. This article is an open access article distributed under the terms and conditions of the Creative Commons Attribution (CC BY) license (https:// creativecommons.org/licenses/by/ $4.0 /)$.

\begin{abstract}
Dropwise condensation is considered to be an effective method of enhancing heat transfer due to its high heat transfer performance. However, because the effect of dropwise condensation is affected by many complex factors, there is no systematic review summarized on the law of dropwise condensation heat transfer by scholars. In this paper, the main methods and problems of promoting dropwise condensation were reviewed based on the dropwise condensation mechanism and theoretical model. The three different hypotheses about the mechanism of dropwise condensation and the heat transfer model of dropwise condensation based on the hypothesis of nucleation sites were summarized. The methods for promoting dropwise condensation and the problems that influence dropwise condensation heat transfer are introduced in this paper. The research showed that many researchers focused on how the surface fabricated forms dropwise condensation rather than whether it enhances heat transfer. In this paper, we point out that the droplet shedding rate is the key to enhancing dropwise condensation heat transfer. Much more research on droplet formation mechanisms and theoretical models of different surfaces is supposed to be carried out in the future.
\end{abstract}

Keywords: dropwise condensation; heat transfer model; surface modification; enhanced heat transfer

\section{Introduction}

Heat transfer enhancement is a hotspot in the research of energy conservation, and with hylology development, more and more materials and methods are introduced in this traditional subject. For enhancing heat transfer between the fluid and surface, much research introduced some new materials into the fluid, such as nanofluids [1-3]. Using new materials to modify the surface can also considerably improve the heat transfer performance, and condensation heat transfer is one of the prime beneficiaries.

The condensation phenomenon exists widely in our daily life and industrial production, such as power generation, water desalination, and condensation of flue gas. There are two different condensation forms of condensing surfaces due to the different wettability. For filmwise condensation (FWC), the condensate can wet the surface well. During the condensation process, a continuous liquid film flowing downward will be formed and the steam must pass through this film to exchange heat of the surface. It will increase the thermal resistance of heat transfer, and thus the heat transfer capability is limited. Dropwise condensation (DWC) was first proposed by Schmidt [4] in the 1930s. Compared with FWC, DWC cannot form a continuous liquid film; thus, there is no liquid film thermal resistance. DWC involves droplets nucleation, growth, coalescence, and departure (shedding, sliding, or jumping) of droplets at a critical size $(\sim 1 \mathrm{~mm})$. DWC has a better heat transfer effect because the dropping of liquid drops increases the disturbance of condensation heat transfer. Therefore, it was recognized as an effective method for enhancing condensation heat transfer.

Condensation forms are influenced by the surface characteristics (structural, material) and condensate characteristics. DWC can be promoted by adding condensable gas to the steam or surface modification technique. When the mixed steam (steam is added with 
alcohol, ammonia, methanol, or refrigerant that can condense and has a low boiling point) condenses on the surface, Marangoni disturbance will occur in the liquid film. Because the mixed liquid with different boiling points has different surface tension, it will bring about the rupture of the liquid film and produce Marangoni dropwise condensation $[5,6]$. Adding other gases to the steam will inevitably cause the pollution of the steam, so it does not hold well for all cases. By contrast, the surface modification techniques promote dropwise condensation by coating the surface, changing the material near the surface, or changing the structural characteristics of the surface. It has better industrial application prospects because it is easier to realize and has better applicability for complex surfaces and complex working conditions.

Promoting dropwise condensation is aimed at enhancing heat transfer of condensation but realizing DWC does not mean that the heat transfer has been enhanced. For example, for the condensate frost problem of refrigerating machine, if the drops cannot fall off in time, they will solidify on the surface, which may lead to a sharp decline in heat transfer efficiency. Accelerating droplet shedding rate will avoid solidifying the refrigerator and have an important significance of enhanced heat transfer of DWC. The heat transfer of DWC reaches a maximum value of the initial stage of condensation. With the growth of droplets, the heat flux gradually decreases, and the instantaneous heat flux when droplets depart also reaches a high point [7]. Therefore, the smaller the drop radius of departure is, the better the heat transfer effect will be. On the other hand, in the process of condensation, the ideal continuous DWC occurs only under the condition of low subcooling. With the increase in the heat flux, the condensation mixing of FWC and DWC will occur. Accelerating droplet shedding rete can delay the transition from DWC to FWC, which maintains the DWC at a higher subcooling degree. Therefore, making condensate droplets shedding in time is the key to realizing continuous DWC and enhancing the heat transfer of the surface.

At present, the condensation form of condensing equipment's surface such as steam turbine condenser, water desalination condenser, and air conditioning condensing systems are still FWC. If it is possible to promote dropwise condensation and accelerate droplet shedding, it will be an effective way to improve heat exchange efficiency and save energy, which has an important significance and broad prospects in industrial application. In this review, to facilitate a quick understanding of DWC, we introduce its mechanism and mathematical heat transfer model. Then, we introduce several kinds of surface modification techniques that were commonly used for promoting dropwise condensation, with an analysis of their advantages and disadvantages. Finally, to solve the problems of dropwise condensation, we briefly introduce some methods.

\section{The Mechanism of Dropwise Condensation}

\subsection{Dropwise Condensation and Its Forming Decision}

Different surfaces have different condensation forms because of their characters. Filmwise condensation forms a continuous liquid film on the surface, but dropwise condensation forms small droplets [4].

In general, the condensation forms (dropwise or filmwise) on the surface are determined by the surface's wettability. According to the surface wettability, the surface can be classified into either a hydrophilic surface, hydrophobic surface, or superhydrophobic surface. The droplet morphology on the surface with different wettability is shown in Figure $1 \mathrm{a}$, when the contact angle is $\theta<90^{\circ}$, the surface is considered a hydrophilic surface, and for filmwise condensation, when the contact angle is $\theta>90^{\circ}$, the surface is considered a hydrophobic surface and forms dropwise condensation [8]. When the contact angle is $\theta>150^{\circ}$ and the rolling angle is less than $10^{\circ}$, the surface is considered a superhydrophobic surface. The rolling angle above is the critical value of the angle $\alpha$ formed between the inclined surface and the horizontal surface when the droplet begins rolling off. When the inclined angle is less than the rolling angle, the droplet will depart due to gravity. As shown in Figure 1b, the advancing and backward contact angles get bigger and smaller. Where the 
$\theta_{a}$ is the advancing contact angle, $\theta_{r}$ is the receding contact angle, and the $\Delta \theta=\theta_{a}-\theta_{r}$ is the contact angle hysteresis.

\section{a}

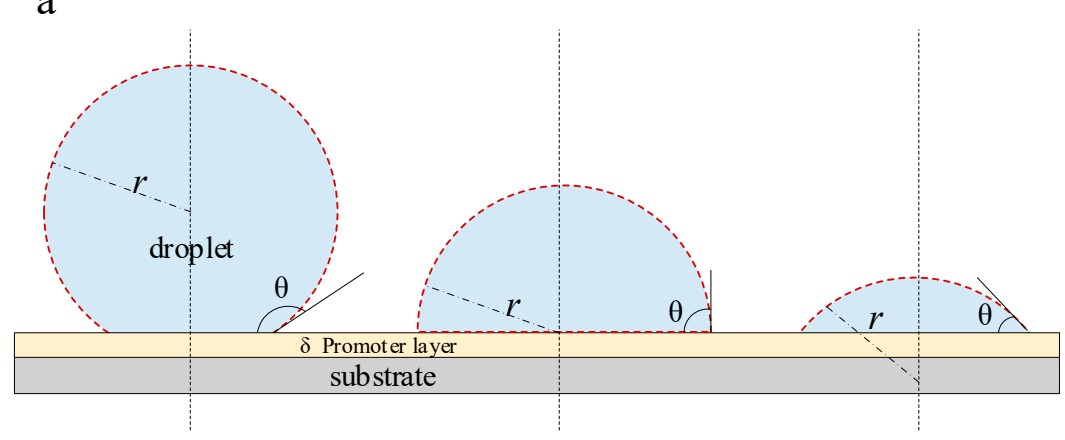

b

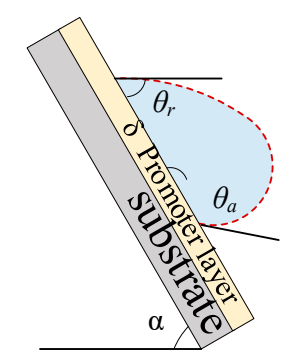

Figure 1. The contact angle of the droplets on different surfaces: (a) surface contact angle; (b) advancing contact angle and receding contact angle.

However, some scholars found that some surfaces can still promote complete dropwise condensation when the contact Angle is less than 90 [9]. Ma [10] proposed that the form of condensation can be classified according to the difference between the surface and liquid free energy $\Delta \gamma$, where $\Delta \gamma=\gamma_{l}-\gamma_{s}$. When $\Delta \gamma \leq 0 \mathrm{MJ} / \mathrm{m}^{2}$, it forms filmwise condensation, when $0 \leq \Delta \gamma \leq 33.3 \mathrm{MJ} / \mathrm{m}^{2}$, is the coexistence state of filmwise condensation and dropwise condensation, when $\Delta \gamma \geq 33.3 \mathrm{MJ} / \mathrm{m}^{2}$, it forms absolute dropwise condensation. Compared with the conventional contact angle method, this method is not restricted to contact angle measurement, which is its main advantage.

\subsection{Research on The Mechanism of Dropwise Condensation}

There are three different hypotheses about the mechanism of dropwise condensation. Firstly, Jakob [11] put forward the theory of liquid film breaks. He believed that the condensate always condenses in the form of a film in the previous condensation process, and the heat transfer can only pass through the liquid film at this time. As the condensation process proceeds, the thickness of the liquid film gradually thickens. When the thickness of the liquid film reaches a critical value, it will break. This phenomenon is due to surface tension, and the liquid film turns into many small droplets. At this time, some parts of the steam directly condense on the surface; otherwise, the steam will condense onto other droplets, causing the droplets to grow until departure. The route of droplets departure will form a bare belt. The above process repeats on a bare surface. However, this theory cannot explain why droplets are more likely to occur in some places. Using a microscope, this theory has been further questioned, and a nucleation sites theory has been suggested.

The nucleation sites theory holds that dropwise condensation, like boiling, is a nucleation phenomenon. There are many condensation cores randomly distributed among the surface. Steam initially condenses at the condensation core to form initial droplets. The diameter of these initial droplets is smaller than the distance between the condensation cores, so the initial droplets are independent of each other. With the further development of the condensation process, steam is condensed on the initial droplets, making the initial droplets grow up. Then heat is mainly transferred to the surface through the thin area of the 
droplet edge. When the droplets grow large enough, they will begin to coalesce and depart. McCorimick [12], Umur [13], and Baer [14] observed the condensation phenomenon via a microscope, combined with theoretical analysis, and then provided strong support for the nucleation sites theory. However, with only a few molecular thicknesses on the surface, the liquid film cannot be observed by microscope, so it is impossible to determine whether there is a liquid film between the droplets.

With the further development of technology, reflection spectroscopy has been applied to the study of dropwise condensation mechanism. Song [15] first put forward the adsorption theory by reflection spectroscopy, which is, both the liquid film and droplets exist on the condensation surface. This theory is a combination and improvement based on the first two theories. According to the adsorption theory, there is a thin liquid film and many condensation cores of the condensation process. The heat transfer rate is mainly carried out by the liquid film, the droplets on the condensation core absorb the condensate from the liquid film continuously and simultaneously as per the adsorption theory, and the droplets on the condensation core also grow until departure. The route of droplets departure will from a film belt. Ma $[16,17]$ also observed the condensation process of the experiment and agreed with this theory. More and more scholars have recognized the adsorption theory because of its more scientifically based observations.

\section{Dropwise Condensation Heat Transfer Model}

Unlike filmwise condensation, dropwise condensation is a discrete phase transition process in which droplets grow in random sites on the surface and then coalesce and depart. This characteristic of dropwise condensation makes it difficult to simulate the overall heat transfer characteristics by computational fluid dynamics (CFD). Based on this problem, many scholars usually establish a one-dimensional heat transfer model of a single liquid droplet and then use the statistic method (population balance) to predict the whole surface's overall heat transfer coefficient.

\subsection{Surface Integral Heat Transfer Model}

In the previous mathematical modeling process of the dropwise condensation, most refer to the nucleation sites theory. They make assumptions of the surface between droplets, think that it is a bare surface, and regard the heat transfer process as the convective heat transfer process of the plate. According to the Nusselt theory [18], $N u_{x}=0.664 \operatorname{Re}_{x}^{1 / 2} \mathrm{Pr}^{1 / 3}$ $\left(R e<5 \times 10^{5}\right)$ and formula $N u_{x}=h_{F} x / \lambda$, the surface convective heat transfer coefficient $h_{F}$ can be obtained. The heat transfer rate of the bare surface can be calculated as

$$
\Phi_{F}=A_{F} h_{F} \Delta \mathrm{T}
$$

where $A_{F}$ is the exposed area of condensation surface, $\mathrm{m}^{2}$, and $\Delta \mathrm{T}$ is the temperature drop between steam and surface, $K$.

For the calculation of the heat transfer rate of the surface covered by the droplets, a one-dimensional heat transfer model of the arbitrary radius droplet can be established. The statistical method (population balance) is introduced to predict the droplet size distribution of the surface, that is, the number of droplets of radius $r$ on the surface, and then the heat transfer rate through all droplets on the surface can be expressed as

$$
\Phi_{D}=A_{D}\left(\int_{r_{\text {min }}}^{r_{e}} q_{d}(r) n(r) d r+\int_{r_{e}}^{r_{\max }} q_{d}(r) N(r) d r\right)
$$

where $n(r), N(r)$ are the population density of small drops and large drops, and as shown by Equations (8) and (9) respectively, $\mathrm{m}^{-3} \cdot q_{d}(r)$ is the heat transfer rate of a droplet and is derived by building a heat transfer model through a single droplet as shown by Equation (7), $\mathrm{W}$. $A_{d}$ is the area covered by droplets on the condensing surface, $\mathrm{m}^{2}$. For the limits of integration, $r_{\min }, r_{e}, r_{\max }$ are the minimum radius, the effective radius, and the maximum radius of the droplet, respectively. These three radii play an important role in the calculation 
of dropwise condensation heat transfer. It is affected by the condensation temperature, the physical properties of the condensate, and the properties of the condensing surface.

(1) Minimum Radius

For a given surface undercooling, there is an ideal minimum droplet size of the condensing surface. In the nucleation stage, condensation and evaporation of vapor molecules form on the surface of the embryo. Only when the drops reach a certain size and the condensation rate is higher than the evaporation rate, can it finally grow [19]. The minimum droplet radius can be expressed by the following equation [20].

$$
r_{\text {min }}=\left(\frac{2 T_{S} \sigma}{H_{f g} \rho}\right) \frac{1}{\Delta \mathrm{T}}
$$

where $T_{S}$ is vapor saturation temperature, K. $\sigma$ is the surface tension of the drop, N/m. $H_{f g}$ is the latent heat of condensation, $\mathrm{J} / \mathrm{kg}$. $\rho$ is the density of the liquid, $\mathrm{kg} / \mathrm{m}^{3}$.

(2) Effective Radius

According to the nucleation sites theory of dropwise condensation, two kinds of drop growth form on the surface. One is small drops that are directly condensed by vapor; the other is large drops that grow by coalescing small drops. The effective droplet radius for determining the droplet size can be obtained by the following [21]:

$$
r_{e}=\sqrt{1 / 4 N_{s}}
$$

where $N_{S}$ is the number of nucleation sites per unit area on the condensing surface.

(3) Maximum Radius

Kim [22] analyzed the force on droplets on the vertical surface, comprehensively considered the influence of contact angle, contact angle hysteresis, and the drop physical properties, and then obtained the droplet departure radius as follows:

$$
r_{\text {max }}=\left(\frac{6\left(\cos \theta_{r}-\cos \theta_{a}\right) \sin \theta}{\left(2-3 \cos \theta+\cos ^{3} \theta\right)} \frac{\sigma}{\rho g}\right)^{1 / 2}
$$

where $\theta$ is the contact angle, $\mathrm{deg}, \theta_{r}, \theta_{a}$ are the receding contact angle and advancing contact angle of the droplet, respectively, and $g$ is the acceleration of gravity, $\mathrm{m} / \mathrm{s}^{2}$.

$\mathrm{Hu}$ [23] improved the formula for maximum radius and increased the influence of the angle of surface inclination, which can be expressed as follows

$$
r_{\text {max }}=\left(\frac{3\left(\cos \theta_{r}-\cos \theta_{a}\right) \sin \theta}{2 \sin \alpha\left(2-3 \cos \theta+\cos ^{3} \theta\right)} \frac{\sigma}{\rho g}\right)^{1 / 2}
$$

where $\alpha$ is the angle of inclination, deg.

Xie [24] considered the three different droplet departures (droplet sliding, rolling, and jumping, as shown in Figure 2) and improved the formula for the maximum droplet radius of the three different departures, respectively.

The heat transfer rate of all droplets can be calculated by Equation (2) after calculating the heat flux of a single droplet and the size distribution function of the surface. 
a

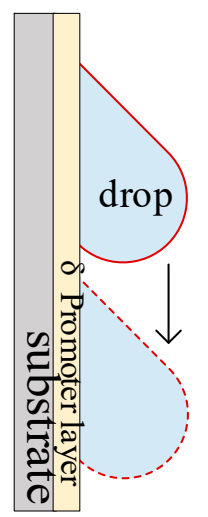

b

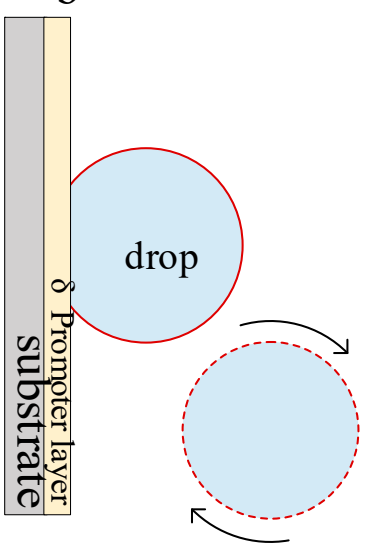

c

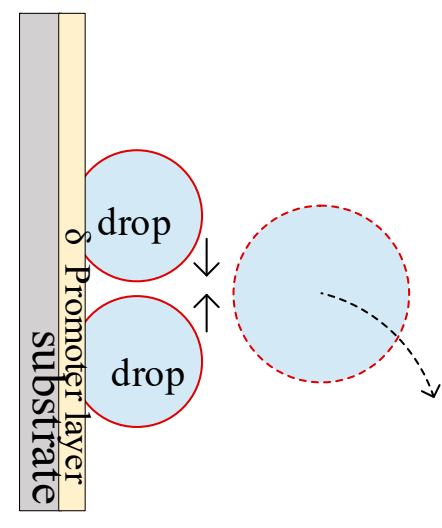

Figure 2. Schematic diagram of three different droplet departure modes: (a) sliding; (b) rolling; (c) jumping.

\subsection{Single Drop Heat Transfer Model}

Rose [25] was the first man to put forward a relatively complete model of dropwise condensation. When he established the mathematical model for the heat transfer rate of a single liquid droplet, he considered that the thermal resistance is composed of the vapor-liquid interfacial resistance $\Delta R_{i}$, the resistance due to the conduction through the drop itself $\Delta R_{d}$, the resistance from the promoter layer $\Delta R_{p}$, and the resistance due to the curvature of the drop of the liquid-vapor interface $\Delta R_{c}$, as shown in Figure 3. In this model, the convective heat transfer within the droplet is negligible. However, for the above model, each drop is rationally treated, and it is believed that the drop is hemispherical and the contact angle of the droplet is $90^{\circ}$, which is obviously not practical. Therefore, Kim [22] improved the Rose model and established a brand-new mathematical model by considering the influence of surface contact angle. Considering the four thermal resistances in the heat transfer process, the heat transfer rate corresponding to a fixed droplet radius $r$ can be expressed using the following equation.
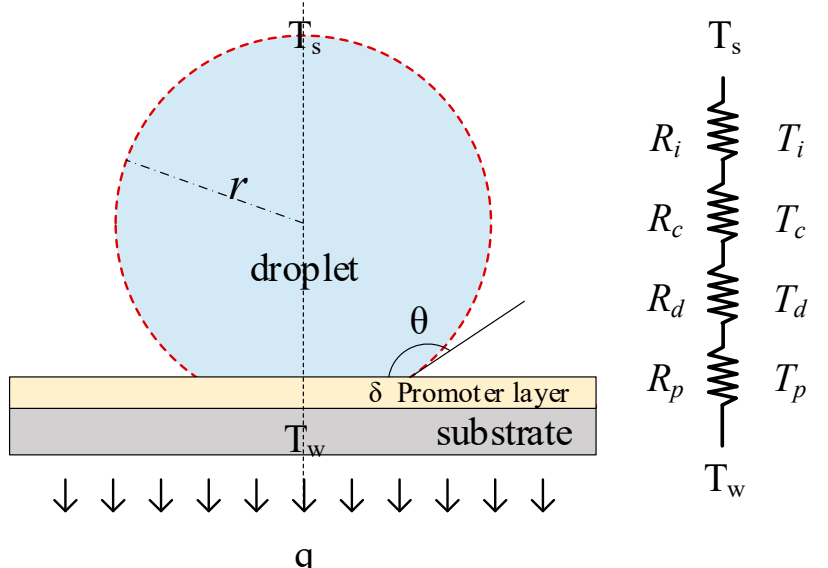

Figure 3. Schematic diagram of thermal resistance network of a single droplet.

$$
q_{d}=\frac{\Delta \mathrm{T} \pi r^{2}\left(1-r_{\min } / r\right)}{\left(\frac{\delta}{k_{\text {coat }} \sin ^{2} \theta}+\frac{r \theta}{4 k_{c} \sin \theta}+\frac{1}{2 h_{i}(1-\cos \theta)}\right)}
$$

where $h_{i}$ is the interface heat transfer coefficient (mainly determined by vapor pressure), $\mathrm{W} /(\mathrm{m} \cdot \mathrm{K}), k_{c}$ is the thermal conductivity of condensate, $\mathrm{W} /(\mathrm{m} \cdot \mathrm{K}), k_{\text {coat }}$ is the thermal 
conductivity of the coating material, $\mathrm{W} /(\mathrm{m} \cdot \mathrm{K}), \delta$ is the thickness of promoter layer, and $r$ is the droplet radius, $\mathrm{m}$.

The model established by Kim [22] is only applicable to smooth surfaces and cannot be well predicted for micro-nano structure surfaces. At present, the surface of the micro-nano structure has complex shape characteristics, so it is difficult to establish a single drop heat transfer model that suits all micro-nano structure surfaces. Therefore, it is a good choice to establish different heat transfer models for different micro-nano structure surfaces. Miljkovic [26], Sangsoo [27], Xiao [28], and Hamid [29] improved the heat transfer model of a single droplet on the surface according to the different morphology of the droplet on different surfaces. With further research, in addition to the four thermal resistances mentioned above, the thermal resistance between solid and liquid is also considered in the heat transfer process, which makes the heat transfer model more accurate [30].

\subsection{Drop Size Distribution}

After establishing the heat transfer model of a single droplet, the heat transfer rate of the whole surface can be calculated by modeling the drop size distribution. Although Gose [31] and Rose [25] proposed a random distribution mathematical model of droplets on the surface early, the population balance theory proposed by Wen [32] and Maa [33] was more accurate and more widely used, and subsequently improved by Mousa [21]. According to this model, the radius of small drops keeps on increasing, but the number of drops on the overall surface is a constant value of the range of $r_{1}$ to $r_{2}$. Based on this theory, the formula of small drop size distribution is

$$
\mathrm{n}(r)=\frac{1}{3 \pi r_{e}^{3} r_{\max }}\left(\frac{r_{e}}{r_{\max }}\right)^{-2 / 3} \frac{r\left(r_{e}-r_{\min }\right)}{r-r_{\min }} \frac{A_{2} r+A_{3}}{A_{2} r_{e}+A_{3}} \exp (B)
$$

where

$$
\begin{aligned}
& A_{1}=\frac{\Delta T}{2 \rho H_{f g}}, \\
& A_{2}=\frac{\theta(1-\cos \theta)}{4 k_{c} \sin \theta},
\end{aligned}
$$

$$
A_{3}=\frac{1}{2 h_{i}}+\frac{\delta(1-\cos \theta)}{k_{\text {coat }} \sin ^{2} \theta}
$$$$
\mathrm{B}=\frac{A_{2}}{\tau A_{1}}\left[\frac{\left(r-r_{\text {min }}^{2}\right)}{2}+2 r_{\text {min }}\left(r-r_{\text {min }}\right)+r_{\text {min }}^{2} \ln \left(r-r_{\text {min }}\right)\right]+\frac{A_{3}}{\tau A_{1}}\left[r-r_{\text {min }}+r_{\text {min }} \ln \left(r-r_{\text {min }}\right)\right]
$$$$
\tau=\frac{3 r_{e}^{2}\left(A_{2} r_{e}+A_{3}\right)^{2}}{A_{1}\left(11 A_{2} r_{e}^{2}-14 A_{2} r_{e} r_{\text {min }}+8 A_{3} r_{e}-11 A_{3} r_{\text {min }}\right)}
$$

where $\tau$ is sweeping period, s.

The distribution model of Rose [25] is still adopted for the droplets grown by coalescing.

$$
\mathrm{N}(\mathrm{r})=\frac{1}{3 \pi r^{2} r_{\max }}\left(\frac{r}{r_{\max }}\right)^{-2 / 3}
$$

Although the above theory only remodels the small drop size distribution, it significantly improves the accuracy of the overall heat transfer model because most of the heat transfer rate transferred to the condensing surface through the small droplets in the condensation process.

Substituting Equations (7)-(9) into Equation (2), we can obtain the heat transfer rate $\Phi_{D}$ through all the droplets, and we can derive the expression of the heat transfer rate of the surface as $\Phi=\Phi_{F}+\Phi_{D}$.

Many in-depth studies have been carried out on the heat transfer model and the adsorption theory has been applied to more scientific observation methods, which has been recognized by more and more scholars. However, up to now, the dropwise condensation heat transfer model is generally based on the nucleation sites theory, and no one has 
established any models based on absorption theory. In addition, there is no applicable and universal heat transfer model for the combination surfaces that have been studied a lot at present, including the influence of droplets between two surfaces with different characteristics and the migration of droplets between surfaces.

\section{Methods, Problems, and Solutions for Promoting Dropwise Condensation 4.1. Methods for Promoting Dropwise Condensation}

Surface modification techniques are the main methods of promoting dropwise condensation because it has bright industrial application prospects. It can be done in two ways: building low free energy surfaces and building micro-nano structure surfaces. According to the basis proposed by Ma [34], it can determinate condensation form by the difference between the free energy of the surface and liquid, so the stable dropwise condensation can be realized by reducing the condensate surface free energy to improve $\Delta \gamma$. At the same time, scholars have found that there are many natural hydrophobic surfaces, such as cicada wing, lotus leaf, and so on. By studying these natural surfaces, it is found that there are many micro-nano structures on the surface, on which droplets can be suspended to achieve dropwise condensation. Therefore, fabricating micro-nano structure surfaces is another main method of promoting dropwise condensation by surface modification technique.

\subsubsection{Low Free Energy Surfaces}

Metallization is an effective method of reducing surface free energy; it can be achieved by plating some precious metals, such as gold, silver, palladium, rhodium, and so on. Some scholars believe that the surface of gold and other noble metals is a natural dropwise condensation surface [35,36]. Wilkins [37] and Holden [38] believed that the adsorption of organic substances in the vapor was the cause of the dropwise condensation property of the gold surface, and for the pure vapor condition, the gold surface formed filmwise condensation. Dropwise condensation can also be achieved by chromium plating on the metal surface [39], which saves costs to some extent. At present, the popular metallization methods are electroplating and electroless plating; the latter is generally considered to be quicker and with a longer life. The surface metallization method is longer than the other coating, and the thermal resistance are small, but the cost of the noble metal is too high, and the life of the chromium plating cannot be guaranteed. At the same time, the electroplating chromium plating can also form chrome, which easily causes environmental pollution.

Zhao $[40,41]$ proposed the method of reducing surface free energy by ion implantation. He injected nitrogen, argon, helium, hydrogen, and other elements into the condensed surface and promoted dropwise condensation. For ion implantation, firstly, the specific elements are ionized into ions in the ion source. The ions selected by the magnetic mass analyzer are accelerated in the high voltage electric field and bombard the metal surface. The surface is bombarded to form an amorphous state, and then surface energy is reduced. Recently, Kiwook [42] successfully injected chromium ions into the aluminum substrate and promoted dropwise condensation. For this surface, the lifetime can exceed half a year. This method has an obvious strengthening effect and can realize large-scale production, but it will destroy the substrate.

Dropwise condensation can also be achieved using organic polymer coating, which is considered the most effective method for achieving long-term stable dropwise condensation [43]. Commonly, polymer coating materials are polymer of fluorocarbon polymer, Silica gel polymer, Hexamethyldisiloxane polymer [44], Benzotriazoles [45] et al. Fluorocarbon polymer such as polytetrafluoroethylene (PTFE) [38], Fluorinated propylene polymer [38], Poly (p-xylene) polymers, and polyhexafluoropropylene [44,46] can promote dropwise condensation on the surface. Fluorocarbons have low thermal conductivity and will produce a high thermal resistance when used as coatings. Hence, the thickness of the coating should be as thin as possible. However, thin coating means low service life. Compared with other fluorocarbon polymers, PTFE has a longer service life with a smaller thickness ( $1 \mu \mathrm{m}$ versus about $10 \mu \mathrm{m}$ for others), making it more promising. Polymer coat- 
ings can be fixed on surfaces by using the splash technology, electro-deposition, vacuum deposition, self-assembled coating [47], plasma polymerization [48], initiated chemical vapor deposition (iCVD) [49], and deposition [50]. In order to reduce the coating thickness under the premise of ensuring the lifetime, the coated surface can be further treated by ion implantation technology, bombarded with a high-energy ion beam to enhance the stability further.

The main methods for reducing surface free energy and their advantages and disadvantages are shown in Table 1.

Table 1. Main methods for reducing surface free energy.

\begin{tabular}{|c|c|c|c|c|}
\hline Methods & Materials Used & $\begin{array}{c}\text { Manufacturing } \\
\text { Process }\end{array}$ & Advantages & Disadvantages \\
\hline \multirow[t]{2}{*}{ Metallization } & $\begin{array}{c}\text { Gold. } \\
\text { Silver. } \\
\text { Palladium. } \\
\text { Rhodium } \\
\text { (Noble metals) }\end{array}$ & $\begin{array}{l}\text { Electroless } \\
\text { plating, } \\
\text { Electroplate }\end{array}$ & $\begin{array}{l}\text { Long life. } \\
\text { No additional } \\
\text { thermal } \\
\text { resistance. } \\
\text { Simple } \\
\text { processing. } \\
\text { No pollution }\end{array}$ & $\begin{array}{l}\text { Difficult to maintain } \\
\text { continuous } \\
\text { dropwise } \\
\text { condensation under } \\
\text { pure steam. } \\
\text { High cost. } \\
\text { Difficult to } \\
\text { industrialize. } \\
\text { Effect decreases } \\
\text { after oxidation }\end{array}$ \\
\hline & Chromium & $\begin{array}{l}\text { Electroplate. } \\
\text { Ion plating }\end{array}$ & $\begin{array}{l}\text { Low cost. } \\
\text { Good thermal } \\
\text { conductivity }\end{array}$ & $\begin{array}{l}\text { Easy to be oxidized. } \\
\text { Difficult to maintain } \\
\text { dropwise } \\
\text { condensation in } \\
\text { pure steam. } \\
\text { Electroplating may } \\
\text { cause pollution }\end{array}$ \\
\hline $\begin{array}{c}\text { Ion } \\
\text { implantation }\end{array}$ & $\begin{array}{l}\text { Nitrogen. Argon, } \\
\text { Helium. Hydrogen. } \\
\text { Chromium et al. }\end{array}$ & $\begin{array}{l}\text { Ions bombard } \\
\text { surface }\end{array}$ & $\begin{array}{c}\text { Enhanced heat } \\
\text { transfer effect } \\
\text { is obvious. } \\
\text { Easy to } \\
\text { industrialize }\end{array}$ & $\begin{array}{l}\text { Will destroy the } \\
\text { substrate. } \\
\text { Anti-erosion is not } \\
\text { guaranteed }\end{array}$ \\
\hline $\begin{array}{l}\text { Organic } \\
\text { polymer } \\
\text { coating }\end{array}$ & $\begin{array}{l}\text { Benzotriazoles. } \\
\text { Polymer of } \\
\text { Fluorocarbon. } \\
\text { Silica gel. } \\
\text { Hexamethyldisiloxane }\end{array}$ & $\begin{array}{c}\text { Vacuum } \\
\text { deposition. } \\
\text { Spray } \\
\text { technology. } \\
\text { Plasma poly- } \\
\text { merization. } \\
\text { Self-assembled } \\
\text { coating. } \\
\text { iCVD }\end{array}$ & $\begin{array}{l}\text { Good thermal } \\
\text { stability. } \\
\text { Lower surface } \\
\text { energy. } \\
\text { Anti-erosion. } \\
\text { Low cost. } \\
\text { Mature } \\
\text { technology }\end{array}$ & $\begin{array}{l}\text { Low thermal } \\
\text { conductivity. } \\
\text { High thermal } \\
\text { resistance. } \\
\text { Alternate cooling } \\
\text { and heating easy to } \\
\text { crack off }\end{array}$ \\
\hline
\end{tabular}

\subsubsection{Micro-Nano Structure Surface}

Scholars have discovered that lotus leaves and cicada wings are natural hydrophobic surfaces in recent years, so they have conducted in-depth research on these surfaces' structure characteristics and found that these surfaces are composed of some tiny needlelike structures. Other natural superhydrophobic surfaces also have many micro-nano structures of their surfaces. Inspired by this discovery, researchers have used different methods (such as etching, chemical deposition, etc.) to produce a series of micro-nano structural surfaces. Yang [51], Luo [52], and Mirhosseini [53] used nanosecond laser processing technology (laser etching) to fabricate micro-nano structure on the surface, transforming a hydrophilic titanium surface into a hydrophobic one. Nam [54] fabricated a needle-like micro-nano structure by directly oxidizing a copper surface. 
In addition to the above techniques of direct surface modification, the micro-nano surface can be made by depositing other materials on the surface. The methods, deposition materials, and contact angles of various micro-nano structure surfaces are shown in Table 2. Depositing other materials on the surface can fabricate a variety of micro-nano structure surfaces. Currently, the main structures include nanowires (nanoneedles) [54-59], nanocones [60,61], nanorods [62,63], nanosheets (nanoflowers) [64-66], nanoblocks [9,67,68], and so on. Different micro-nano structure surfaces have different effects on hydrophobicity. The larger the specific surface area of the surface and the stronger the air-trapping ability is, the easier it is to achieve a larger contact angle. This is also why nanowires, nanocones, and nanorods can more easily achieve larger contact angles than nanosheets and nanoblocks. Compared with nanowire structures, nanosheets are more inclined to wire and surface contact with droplets. This phenomenon will cause the droplets to adhere to the micro-nano structure after coalescence so that the droplets are difficult to fall off and the surface has a poor self-cleaning performance. The nanosheet structure becomes rough by silanizing, which can effectively solve the problem of poor self-cleaning performance.

Table 2. Typical micro-nano structures.

\begin{tabular}{|c|c|c|c|c|c|}
\hline Nanostructure & Reference & Methods & Substrate & $\begin{array}{l}\text { Deposition } \\
\text { Materials }\end{array}$ & Contact Angle \\
\hline \multirow{4}{*}{$\begin{array}{c}\text { Nanowires } \\
\text { (nanoneedles) }\end{array}$} & [55] & Pyrolysis & Quartz glass & $\begin{array}{c}\text { Carbon } \\
\text { nanotube }\end{array}$ & $161^{\circ}$ \\
\hline & [57] & $\begin{array}{l}\text { Chemical } \\
\text { deposition }\end{array}$ & Cotton & $\mathrm{ZnO}$ & $156^{\circ}$ \\
\hline & [58] & Spray & Copper & $\begin{array}{c}\text { carbon } \\
\text { nanotubes }\end{array}$ & $162^{\circ}$ \\
\hline & [69] & $\begin{array}{l}\text { Chemical } \\
\text { treatment }\end{array}$ & - & $\begin{array}{c}\mathrm{SiO}_{2} \text {-coated } \\
\mathrm{SiC}\end{array}$ & $153^{\circ}$ \\
\hline \multirow{2}{*}{ Nanocones } & {$[60]$} & $\begin{array}{c}\text { Electro- } \\
\text { deposition }\end{array}$ & Copper & $\mathrm{Ni}$ & $153.6^{\circ}$ \\
\hline & {$[61]$} & $\begin{array}{c}\text { Oxygen } \\
\text { plasma etching }\end{array}$ & PTFE & Polystyrene & $144^{\circ}$ \\
\hline \multirow{3}{*}{ Nanorods } & [57] & $\begin{array}{l}\text { Chemical } \\
\text { deposition }\end{array}$ & Cotton & $\mathrm{ZnO}$ & $167.5^{\circ}$ \\
\hline & {$[63]$} & $\begin{array}{l}\text { Chemical } \\
\text { deposition }\end{array}$ & $\begin{array}{l}\text { Glass and } \\
\text { silicon }\end{array}$ & $\mathrm{ZnO}-\mathrm{a}-\mathrm{Gs}$ & 120.8 \\
\hline & {$[70]$} & $\begin{array}{c}\text { Electro- } \\
\text { deposition }\end{array}$ & Zinc & $\mathrm{ZnO}$ & 167 \\
\hline \multirow{4}{*}{ Nanosheet } & [64] & $\begin{array}{c}\text { Electro- } \\
\text { deposition }\end{array}$ & Copper & $\mathrm{C}_{36} \mathrm{H}_{70} \mathrm{CuO}_{4}$ & $130.5^{\circ}$ \\
\hline & & Hydrothermal & Copper & $\mathrm{CuO}$ & $124.7^{\circ}$ \\
\hline & {$[65]$} & Hydrothermal & Copper & $\mathrm{CuO}$ & $172^{\circ}$ \\
\hline & [66] & $\begin{array}{l}\text { Chemical } \\
\text { deposition }\end{array}$ & $\begin{array}{l}\text { Fluorine doped } \\
\text { tin oxide }\end{array}$ & $\mathrm{SnO}_{2}$ & $125^{\circ}$ \\
\hline \multirow{3}{*}{ Nanoblock } & [9] & $\begin{array}{l}\text { Chemical } \\
\text { vapor } \\
\text { deposited } \\
\text { (CVD) }\end{array}$ & Copper & $\begin{array}{l}\text { Nano } \\
\text { graphene } \\
\text { particles }\end{array}$ & $87^{\circ}$ \\
\hline & [67] & $\begin{array}{l}\text { Spray } \\
\text { pyrolysis }\end{array}$ & Glass & $\mathrm{ZnO}$ & $154^{\circ}$ \\
\hline & {$[68]$} & Direct melt & Ceramic & $\begin{array}{l}\text { Rare Earth } \\
\text { Oxide }\end{array}$ & $100^{\circ}-120^{\circ}$ \\
\hline
\end{tabular}

For this method of fabricating micro-nano structure surfaces, different experimental environments, substrate, and operation methods may produce different effects. For example, Li [55] fabricated an array of carbon nanotube films on the surface of quartz glass sheets by the high-temperature pyrolysis method, with the contact angle with water as high 
as $161^{\circ}$ and the contact angle after fluorosilane treatment as $172^{\circ}$. However, the surface hydrophobicity obtained by Song [56] using the same method of the copper substrate was only $134^{\circ}$.

Many scholars focused on how to achieve dropwise condensation during the process of promoting dropwise condensation by surface modification but neglected another question: can dropwise condensation enhance heat transfer? What are the main reasons that dropwise condensation enhances heat transfer?

\subsection{The Main Problem of Enhancing the Heat Transfer of Dropwise Condensation}

There are two main problems with dropwise condensation enhancing heat transfer; the first one is hydrophilic or hydrophobic. Hydrophilic and hydrophobic surfaces play different and equally important roles in the condensation process. The hydrophilic surface is the key to promote the nucleation rate of a droplet, and the hydrophobic surface is the necessary condition to obtain the dropwise condensation and larger heat transfer coefficient. The second one is how to speed up the droplet departure rate and maintain a stable dropwise condensation. For a certain surface, the droplet departure rate has a limit. With the increase in surface subcooling temperature $\Delta \mathrm{T}$, the steam condensation rate will exceed the droplet departure rate. This will cause droplet deposition on the surface and change the condensation formed dropwise condensation into filmwise condensation. For example, in the process of condensation, filmwise condensation is more likely to occur at the geometric center of the hydrophobic surface [71,72], which is mainly caused by the fact that droplets at the center cannot fall off in time. The superhydrophobic surface can accelerate droplet departure, which can alleviate the above phenomenon. However, the superhydrophobic surface also has an adverse effect on droplet nucleation. According to the experimental study, compared with the hydrophobic surface, the superhydrophobic surface does not have a good heat transfer effect of the initial stage of condensation, but with time, the superhydrophobic surface has a higher heat transfer coefficient [73].

The droplets have two morphology states on the hydrophobic surface of the micronano structure, namely Cassie state and Wenzel state. The Cassie state (Figure 4a) occurs when the droplet is statically suspended on the structures, in which the droplets easily fall off the surface, but the thermal resistance between the droplets and the surface is larger. The Wenzel state (Figure 4c) forms when the structures underneath the droplet are completely immersed by the liquid, so the contact thermal resistance between the droplets and the surface is smaller, but the droplets do not easily fall off the surface. Miljkovic [74] believed that partial Wenzel (Figure 4b) was the most favorable for heat transfer, which is the intermediate state between Cassie and Wenzel. In the condensation process, droplets will gradually deposit in the pores of microstructures, and the flooding phenomenon will occur. This phenomenon will make the droplet morphology states from Cassie become Wenzel, leading to the superhydrophobic surface losing its surface function. The properties of superhydrophobic surfaces can be regained by drying surfaces [75] or infiltrating oily substances [76] on the micro-nano structures surface, but all of them are palliative methods.

The two problems mentioned above of dropwise condensation affect the droplet nucleation rate and departure rate. Suppose the droplets cannot fall off in time and coalescence on the condensation surface. In that case, the height of the droplets will be much higher than that of the filmwise condensation liquid film, and the thermal resistance of the droplets will also be much higher than that of the liquid film, thus reducing the heat transfer coefficient, impacting the effect of enhancing heat transfer, and even making the heat transfer efficiency of the dropwise condensation lower than filmwise condensation. 

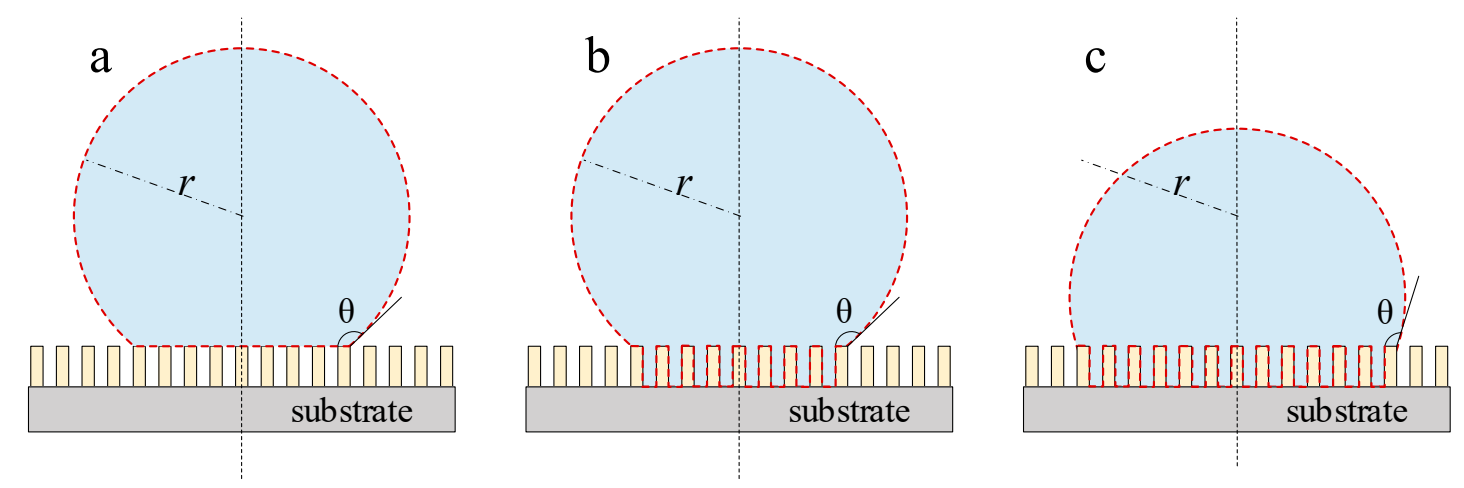

Figure 4. The state of droplets on the surface of the micro-nano structure: (a) Cassie state; (b) Partial Wenzel; (c) Wenzel state.

\subsection{Solutions to Main Problems}

\subsubsection{Composite Surface Method}

Many scholars have studied the condensation heat transfer of a series of patterned surfaces [77-83], such as superhydrophobic-hydrophilic, superhydrophilic-hydrophobic, etc. Masuda [66] transformed the hydrophilic surface to hydrophobic by the method of light radiation (irradiated by a low-pressure mercury lamp in the air). Geng [60] fabricated a Ni nanocones structure surface on copper substrate by electrochemical deposition. Initially, the surface was hydrophilic, but when exposed to room temperature, it was slowly transformed into a superhydrophobic surface. These studies provide a feasible method of fabricating combination surfaces. Peng [82] obtained the strip patterned surface by partially covering the whole hydrophilic surface and hydrophobic treatment of the exposed surface.

The hydrophilic and hydrophobic patterned surfaces combine the advantages of hydrophilic surface nucleation and hydrophobic surface droplet departure rates. It will feature filmwise condensation in the center of the surface. However, the heat transfer effect of the patterned surface will deteriorate in some cases. The distribution of hydrophilic and hydrophobic areas on the surface forms the surface tension gradient. Under surface tension gradients, droplets on hydrophobic areas will migrate to hydrophilic areas (droplet migration) [82] and concentrate on the hydrophilic area. The droplet departure rate will increase the additional thermal resistance. The patterned surface will also influence heat transfer performance, e.g., a striped surface; however, too wide stripe belts will cause the overall heat transfer rate to decline. A narrow stripe belt is conducive to enhancing heat transfer. However, if it is too narrow, the hydrophobic area will be merged by the hydrophilic area's droplets and form a continuous liquid film, reducing the heat transfer effect [83]. The angle between the normal patterned surface and the gravity (the main force due to droplet departure) also affects the surface heat transfer performance [80].

Fabricating micro-nano composite structures of different sizes of the surface is another solution. The advantages of hydrophilic and hydrophobic surfaces are combined by building layered and multi-scale structures that are interlaced with hydrophilic and hydrophobic surfaces. This kind of surface can promote the formation of dropwise condensation better than the pure superhydrophobic surface, and the dropping performance of droplets is better $[78,84]$. Compared with the characteristics of random nucleation on the superhydrophobic surface, the nucleation sites on the surface of this composite structure of the hydrophilic surface are controllable [78]. Such surfaces enhance the hydrophobicity of the surface and postpone heat flux deterioration caused by the droplets' forms changing into a Wenzel shape. Meanwhile, this micro-nano composite structure keeps the efficient droplet characteristics of the hydrophobic surface, so there are a large number of small droplets on the surface. Because steam heat is mainly transferred to the surface through small droplets in the condensation process, the heat transfer efficiency can be significantly improved $[85,86]$. This kind of surface avoids filmwise condensation as far as possible, but 
the droplet departure rate still has a superior limit; with the temperature drop increase, the heat flux will be reduced [87].

\subsubsection{Increased Driving Force Promotes Droplet Shedding}

According to Kim's heat transfer model [22] mentioned above, the dropwise condensation heat flux is simulated for the contact angles of $90 \mathrm{deg}, 120 \mathrm{deg}, 150 \mathrm{deg}$ in Figure 4. For the calculation, the following conditions were used: The vapor saturation temperature was $375 \mathrm{~K}$, the nucleation density was $2.5 \times 10^{11} \mathrm{~m}^{-2}$, and thermal conductivity and thickness of the promoter layer were $0.2 \mathrm{~W} /(\mathrm{m} \cdot \mathrm{K})$ and $1 \mu \mathrm{m}$, respectively. In Figure 5, with the increase of the sweeping time, the heat flux decreases rapidly, and the decrease rate is faster with the increase of contact angle. It is obvious that increasing the droplet shedding rate can significantly enhance the dropwise condensation heat flux for the contact angles of $90 \mathrm{deg}, 120 \mathrm{deg}$, and $150 \mathrm{deg}$. Increasing the droplet shedding rate means that the mass transfer rate is increased and will decrease the thermal resistance due to the conduction through the drop itself. To increase the droplet shedding, decreasing the maximum droplet radius is an effective method. For the three curves in Figure 5, when the sweeping period is $5.5 \mathrm{~s}$, The maximum heat flux is found on the condensation surface with a contact angle of $90 \mathrm{deg}$. When the subcooling is $11 \mathrm{~K}$, the heat flux on the surface of the condensation with a contact angle of $150 \mathrm{deg}$ is the largest.

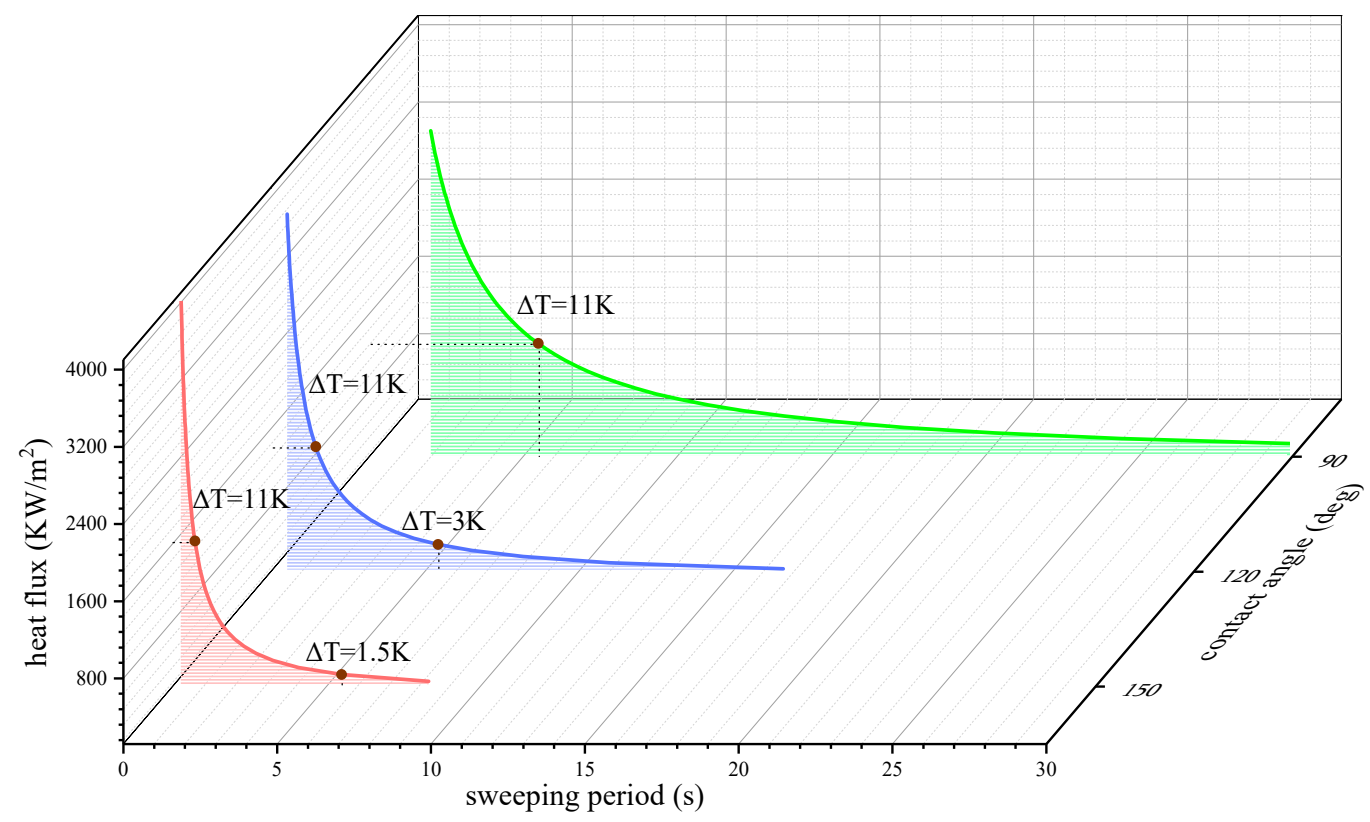

Figure 5. Dropwise condensation heat flux with respect to the sweeping period and contact angle.

Therefore, for a certain surface, speeding up droplet shedding is the key to enhancing dropwise condensation heat transfer. In general, gravity is the mainly driving force for droplets falling off. How can speed up droplets departure rate by increasing driving force has been studied.

Daniel [88] found that the droplets can also move spontaneously on the horizontal surface. He prepared radial surface with surface tension gradients on the condensed surface by diffusion-controlled silanization. The treated surface generated droplet migration and promoted droplet shedding, the maximum migration velocity of the droplet on the prepared horizontal surface can be up to $1.5 \mathrm{~m} / \mathrm{s}$. Using surface energy gradient as the driving force to accelerate the shedding of droplets is a typical passive method without other energy consumption. Once the technology is mature, it will greatly enhance the heat transfer of dropwise condensation. 
For the superhydrophobic surface, Boreyko and Chen [89] reported the self-propelled jumping during condensation. They believed that this phenomenon happened because the drops coalesce and release excess surface energy, which drives the drops to jump by turning into kinetic energy. Many scholars have researched this phenomenon [7,65,90-93]. For this phenomenon, the larger number of coalesced droplets is, the smaller the droplet radius required [90]. The surface mentioned by Boreyko and Chen [89] had a drop jumping diameter of only $10 \mu \mathrm{m}$. The surface fabricated by li [91] found that the droplet diameter when jumping off reaches 20-45 $\mu \mathrm{m}$. He [92] found that the jumping and fall off diameter of droplets was between 14-30.2 $\mu \mathrm{m}$. The drop jumping phenomenon of the superhydrophobic surface makes it have a better self-cleaning property, which can also greatly strengthen the dropwise condensation heat transfer. For surfaces with droplet jumping characteristics, it only can be achieved under the condition of low heat flux, but with the increase of heat flux, the phenomenon of droplet jumping cannot be well maintained [65]. Milijkovic [93] found that condensate droplets are electrically charged when they are jumping. Inspired by this phenomenon, Yan [94] applied a tangential alternating current electric field to the condensing surface to increase the droplets shedding rate, and this method could realize the jumping shedding just by a single droplet, which would greatly enhance the heat transfer performance of the surface.

In addition to the above methods, ultrasonic can also generate a sound suspension of droplets [95], and mechanical vibration can also promote the droplets dropping off from the surface $[96,97]$. Although there are many ways to speed up droplet shedding and slow down the transition from dropwise to filmwise condensation, achieving stable dropwise condensation remains the focus in further research.

\section{Conclusions}

In this paper, the mechanism of dropwise condensation, heat transfer model, main methods of promoting dropwise condensation, main problems, and solutions of dropwise condensation to enhance heat transfer are summarized. The main conclusions are as follows:

(1) A series of problems in the process of dropwise condensation restrict the effect of heat transfer. For dropwise condensation, increasing droplet departure rate is the key to further enhancing heat transfer.

(2) The hydrophilicity and hydrophobicity surface have a great influence on the nucleation and departure of droplets, respectively. The effect of enhancing heat transfer of dropwise condensation can be changed by setting the hydrophilicity and hydrophobicity of the surface.

(3) As for theoretical research on dropwise condensation heat transfer, the dropwise condensation heat transfer model established at present is still based on the nucleation sites theory, and the modeling of the surface with droplet migration and the patterned surface is still blank, and further study should continue in the future.

Author Contributions: Conceptualization, X.H. and Q.Y.; methodology, X.H. and Q.Y.; software, X.H.; validation, X.H., Q.Y., X.K. and J.W.; formal analysis, X.H., Q.Y., X.K. and J.W.; investigation, X.H., and Q.Y. data curation, X.H., Q.Y., X.K. and J.W.; writing-original draft preparation, X.H.; writing-review and editing, X.H. and Q.Y. All authors have read and agreed to the published version of the manuscript.

Funding: This research was funded by NATIONAL NATURAL SCIENCE FOUNDATIONS OF CHINA, grant number 51776115.

Institutional Review Board Statement: This research received no external funding.

Informed Consent Statement: Not applicable.

Data Availability Statement: Data is contained within the article. 
Acknowledgments: This work was supported by the National Natural Science Foundations of China (No. 51776115).

Conflicts of Interest: The authors declare no conflict of interest.

\section{Abbreviations}

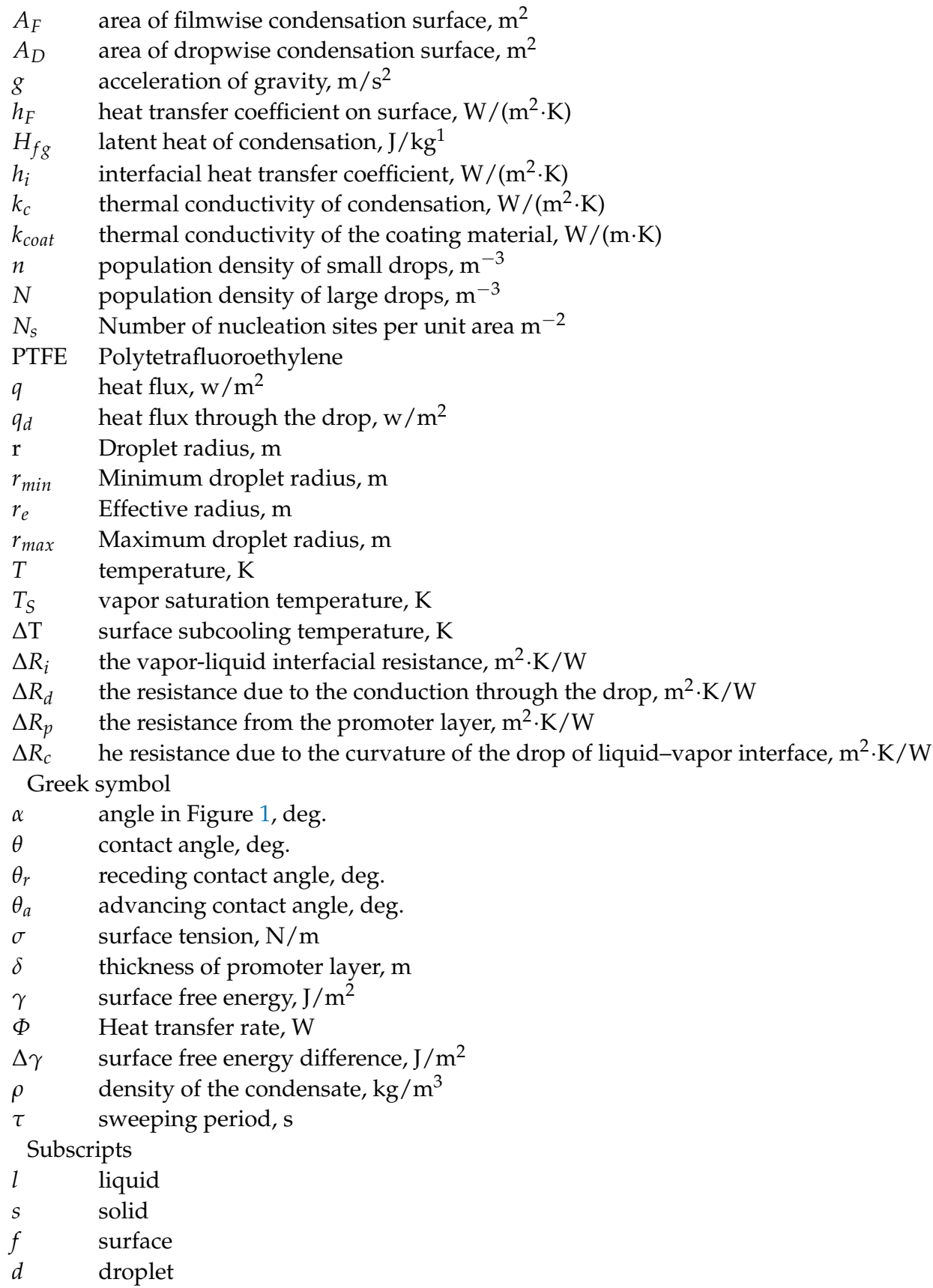

\section{References}

1. Nakhchi, M.; Esfahani, J.A. CFD approach for two-phase $\mathrm{CuO}$ nanofluid flow through heat exchangers enhanced by double perforated louvered strip insert. Powder Technol. 2020, 367, 877-888. [CrossRef]

2. Nakhchi, M.; Esfahani, J. Numerical investigation of heat transfer enhancement inside heat exchanger tubes fitted with perforated hollow cylinders. Int. J. Therm. Sci. 2020, 147, 106153. [CrossRef]

3. Nakhchi, M.; Hatami, M.; Rahmati, M. A numerical study on the effects of nanoparticles and stair fins on performance improvement of phase change thermal energy storages. Energy 2021, 215, 119112. [CrossRef] 
4. Schmidt, E.; Schurig, W.; Sellschopp, W. Versuche über die Kondensation von Wasserdampf in Film- und Tropfenform. Tech. Mech. Thermodyn. 1930, 1, 53-63. [CrossRef]

5. Mirkovich, V.V.; Missen, R.W. Non-filmwise condensation of binary vapors of miscible liquids. Can. J. Chem. Eng. 1961, 39 , 86-87. [CrossRef]

6. Ali, H.; Kamran, M.; Imran, S. Condensation heat transfer enhancement using steam-ethanol mixtures on horizontal finned tube. Int. J. Therm. Sci. 2019, 140, 87-95. [CrossRef]

7. Wang, X.; Yan, S.; Liu, Q. Experiment for drop-wise condensation heat transfer by infrared thermal imager. Chin. J. Space Sci. 2016, 36, 520-524. (In Chinese)

8. Davies, G.; Mojtehedi, W.; Ponter, A. Measurement of contact angles under condensation conditions. The prediction of dropwisefilmwise transition. Int. J. Heat Mass Transf. 1971, 14, 709-713. [CrossRef]

9. Preston, D.J.; Mafra, D.L.; Miljkovic, N.; Kong, J.; Wang, E.N. Scalable Graphene Coatings for Enhanced Condensation Heat Transfer. Nano Lett. 2015, 15, 2902-2909. [CrossRef]

10. Ma, X.; Chen, J.; Xu, D.; Lin, J. Surface free energy difference criterion for condensation modes. J. Chem. Ind. Eng. 2002, 5, 457-460. (In Chinese)

11. Jakob, M. Heat transfer in evaporation and condensation II. Mech. Eng. 1936, 58, 729-739.

12. McCormick, J.L.; Westwater, J.W. Nucleation sites for dropwise condensation. Chem. Eng. Sci. 1965, 20, 1021-1036. [CrossRef]

13. Mikic, B. On mechanism of dropwise condensation. Int. J. Heat Mass Transf. 1969, 12, 1311-1323. [CrossRef]

14. McCormick, J.L.; Baer, E. On the mechanism of heat transfer in dropwise condensation. J. Colloid Sci. 1963, 18, 208-216. [CrossRef]

15. Yongji, S.; Dunqi, X.; Jifang, L.; Siexong, T. A study on the mechanism of dropwise condensation. Int. J. Heat Mass Transf. 1991, 34, 2827-2831. [CrossRef]

16. Ma, X.; Wang, B.; Xu, D.; Lin, J. Filmwise Condensation Heat Transfer Enhancement with Dropwise and Filmwise Coexisting Condensation Surfaces. J. Chem. Ind. Eng. 1998, 6, 95-102.

17. Ma, X.; Xu, D.; Lin, J. Condensation heat transfer is enhanced on the surface of droplet membrane coexistence. J. Chem. Ind. Eng. 1999, 4, 535-540. (In Chinese)

18. Nusselt, W. Die Oberflachenkodensation des Wasserdampfes. Z. VDI 1916, 60, 569-575.

19. Wen, H.W.; Jer, R.M. On the heat transfer in dropwise condensation. Chem. Eng. J. 1976, 12, 225-231. [CrossRef]

20. Graham, C.; Griffith, P. Drop size distributions and heat transfer in dropwise condensation. Int. J. Heat Mass Transf. 1973, 16, 337-346. [CrossRef]

21. Abu-Orabi, M. Modeling of heat transfer in dropwise condensation. Int. J. Heat Mass Transf. 1998, 41, 81-87. [CrossRef]

22. Kim, S.; Kim, K.J. Dropwise Condensation Modeling Suitable for Superhydrophobic Surfaces. J. Heat Transf. 2011, 133, 081502. [CrossRef]

23. $\mathrm{Hu}, \mathrm{H}$.; Tang, G. Theoretical investigation of stable dropwise condensation heat transfer on a horizontal tube. Appl. Therm. Eng. 2014, 62, 671-679. [CrossRef]

24. Xie, J.; Xu, J.; Shang, W.; Zhang, K. Dropwise condensation on superhydrophobic nanostructure surface, part II: Mathematical model. Int. J. Heat Mass Transf. 2018, 127, 1170-1187. [CrossRef]

25. Rose, J. Dropwise condensation theory. Int. J. Heat Mass Transf. 1981, 24, 191-194. [CrossRef]

26. Miljkovic, N.; Enright, R.; Wang, E.N. Modeling and Optimization of Superhydrophobic Condensation. J. Heat Transf. 2013, 135, 111004. [CrossRef]

27. Lee, S.; Yoon, H.K.; Kim, K.J.; Kim, S.; Kennedy, M.; Zhang, B.J. A dropwise condensation model using a nano-scale, pin structured surface. Int. J. Heat Mass Transf. 2013, 60, 664-671. [CrossRef]

28. Xiao, X.; Fan, X. Heat transfer and growth model of droplet on nano-structured surface. Hebei J. Ind. Sci. Technol. 2018, 3, 164-170. (In Chinese)

29. Bahrami, H.R.T.; Saffari, H. Theoretical study of stable dropwise condensation on an inclined micro/nano-structured tube. Int. J. Refrig. 2017, 75, 141-154. [CrossRef]

30. Niu, D.; Guo, L.; Hu, H.W.; Tang, G.H. Dropwise condensation heat transfer model considering the liquid-solid interfacel thermal resistance. Int. J. Heat Mass Transf. 2017, 112, 324-333. [CrossRef]

31. Gose, E.E.; Mucciardi, A.; Baer, E. Model for dropwise condensation on randomly distributed sites. Int. J. Heat Mass Transf. 1967, 10, 15-22. [CrossRef]

32. Maa, J.R. Drop size distribution and heat flux of dropwise condensation. Chem. Eng. J. 1978, 16, 171-176. [CrossRef]

33. Ma, X.; Song, T.; Lan, Z.; Zhou, X.; Yang, J. Advances in liquid solid interfacial energy difference effect and condensation heat transfer enhancement. J. Chem. Ind. Eng. 2006, 8, 1763-1775. (In Chinese)

34. Ma, X.; Lan, Z.; Wang, A.; Wang, M.; Wang, S. Experimental investigation of characteristics of steam dropwise condensation heat transfer at low pressure. J. Eng. Thermophys. 2010, 3, 483-486. (In Chinese)

35. Erb, R.A. Wettability of Metals under Continuous Condensing Conditions. J. Phys. Chem. 1965, 69, 1306-1309. [CrossRef]

36. Erb, R.; Thelen, E. PROMOTING PERMANENT DROPWISE CONDENSATION. Ind. Eng. Chem. 1965, 57, 49-52. [CrossRef]

37. Wilkins, D.G.; Bromley, L.A.; Read, S.M. Dropwise and filmwise condensation of water vapor on gold. AIChE J. 1973, 19, 119-123. [CrossRef]

38. Holden, K.M.; Wanniarachchi, A.S.; Marto, P.J.; Boone, D.H.; Rose, J.W. The Use of Organic Coatings to Promote Dropwise Condensation of Steam. J. Heat Transf. 1987, 109, 768-774. [CrossRef] 
39. Finnicum, S.S.; Westwater, J. Dropwise vs filmwise condensation of steam on chromium. Int. J. Heat Mass Transf. 1989, 32, 1541-1549. [CrossRef]

40. Qi, Z.; Dongchang, Z.; Jifang, L. Surface materials with dropwise condensation made by ion implantation technology. Int. J. Heat Mass Transf. 1991, 34, 2833-2835. [CrossRef]

41. Zhao, Q.; Burnside, B. Dropwise condensation of steam on ion implanted condenser surfaces. Heat Recover. Syst. CHP 1994, 14, 525-534. [CrossRef]

42. Kim, K.; Lee, Y.; Jeong, J.H. Dropwise condensation induced on chromium ion implanted aluminum surface. Nucl. Eng. Technol. 2019, 51, 84-94. [CrossRef]

43. Tanasawa, I. Advances in Condensation Heat Transfer. Heat Transfer in Nuclear Reacter Safety 1991, 21, 55-139. [CrossRef]

44. Ma, X.; Xu, D.; Lin, J. Dropwise condensation on surperthin polymer surface. J. Chem. Ind. Eng. 1993, 2, 165-170. (In Chinese)

45. Liu, X.; Xu, D. Study of enhancement of condensation heat transfer on Cu-BTA film surface. J. Dalian Univ. Technol. 1996, 2, 162-164. (In Chinese)

46. Ma, X.; Li, H.; Xu, D. A Study of Dropwise Condensation Heat Transfer on the Superthin Polymer Surfaces. J. Chem. Eng. Chin. Univ. 1993, 4, 309-316. (In Chinese)

47. Das, A.K.; Kilty, H.P.; Marto, P.J.; Andeen, G.B.; Kumar, A. The Use of an Organic Self-Assembled Monolayer Coating to Promote Dropwise Condensation of Steam on Horizontal Tubes. J. Heat Transf. 1999, 122, 278-286. [CrossRef]

48. Ma, X.; Xu, D.; Lin, J. Superthin polymer surface for dropwise condensation heat transfer. J. Chem. Ind. Eng. 1993, 3, $277-281$.

49. Paxson, A.T.; Yague, J.L.; Gleason, K.K.; Varanasi, K.K. Stable Dropwise Condensation for Enhancing Heat Transfer via the Initiated Chemical Vapor Deposition (iCVD) of Grafted Polymer Films. Adv. Mater. 2014, 26, 418-423. [CrossRef]

50. He, P.; Wang, L.; Wang, H. Experimental study on enhancement of condensation heat transfer for surface deposited PTFE. J. Chem. Ind. Eng. 2000, 1, 330-334. (In Chinese)

51. Yang, C.; Li, Y.; Mei, X. Study on the fabrication of titanium surface texture by nanosecond laser and its wettability. J. Hebei Univ. Sci. Technol. 2016, 37, 315-321. (In Chinese)

52. Luo, B.; Shum, P.; Zhou, Z.; Li, K. Preparation of hydrophobic surface on steel by patterning using laser ablation process. Surf. Coat. Technol. 2010, 204, 1180-1185. [CrossRef]

53. Mirhosseini, N.; Crouse, P.L.; Schmidth, M.J.J.; Li, L.; Garrod, D. Laser surface micro-texturing of Ti-6Al-4V substrates for improved cell integration. Appl. Surf. Sci. 2007, 253, 7738-7743. [CrossRef]

54. Nam, Y.; Ju, Y.S. A comparative study of the morphology and wetting characteristics of micro/nanostructured Cu surfac-es for phase change heat transfer applications. J. Adhes. Sci. Technol. 2013, 27, 2163-2176. [CrossRef]

55. Li, H.; Wang, X.; Song, Y. Porous Aligned Carbon Nanotube Films for Ultrahydrophobic Surfaces. Chem. J. Chin. Univ. 2001, 5, 759-761. (In Chinese)

56. Song, Y.; Ren, X.; Ren, S. Condensation heat transfer of steam on superhydrophobic sufaces. J. Eng. Thermophys. 2007, 1, 95-97. (In Chinese)

57. Athauda, T.J.; Hari, P.; Ozer, R.R. Tuning Physical and Optical Properties of ZnO Nanowire Arrays Grown on Cotton Fibers. ACS Appl. Mater. Interfaces 2013, 5, 6237-6246. [CrossRef] [PubMed]

58. Luo, X.; Wei, M.; Cao, M. Preparation of Superhydrophobic Cu Mesh with Corrosin Resistance and Applications in Oil-water Separation. J. Mater. Eng. 2018, 46, 92-98. (In Chinese)

59. Torresin, D.; Tiwari, M.K.; del Col, D.; Poulikakos, D. Flow Condensation on Copper-Based Nanotextured Superhydro-phobic Surfaces. Langmuir 2013, 29, 840-848. [CrossRef]

60. Geng, W.; Hu, A.; Li, M. Super-hydrophilicity to super-hydrophobicity transition of a surface with Ni micro-nano cones array. Appl. Surf. Sci. 2012, 263, 821-824. [CrossRef]

61. Toma, M.; Loget, G.; Corn, R.M. Flexible Teflon Nanocone Array Surfaces with Tunable Superhydrophobicity for Self-Cleaning and Aqueous Droplet Patterning. ACS Appl. Mater. Interfaces 2014, 6, 11110-11117. [CrossRef]

62. Fang, X.; Gao, S.; Li, W. Growth and photocatalytic properties of ZnO nanodarrays/p-diamond heterojunction. China Sci. 2015, 10, 2662-2665. (In Chinese)

63. Pahari, D.; Das, N.; Das, B.; Chattopadhyay, K.K.; Banerjee, D. Tailoring the optical and hydrophobic property of zinc oxide nanorod by coating with amorphous graphene. Phys. E: Low-Dimens. Syst. Nanostructures 2016, 83, 47-55. [CrossRef]

64. Li, X.; Qi, B.; Miljkovic, N. Experimental study on condensation heat transfer of copper-based nano-structure hydropbobic surfaces. China Sci. 2017, 12, 1220-1224. (In Chinese)

65. Miljkovic, N.; Enright, R.; Nam, Y.; Lopez, K.; Dou, N.G.; Sack, J.H.; Wang, E.N. Jumping-Droplet-Enhanced Condensation on Scalable Superhydrophobic Nanostructured Surfaces. Nano Lett. 2012, 13, 179-187. [CrossRef]

66. Masuda, Y.; Ohji, T.; Kato, K. Tin Oxide Nanosheet Assembly for Hydrophobic/Hydrophilic Coating and Cancer Sensing. ACS Appl. Mater. Interfaces 2012, 4, 1666-1674. [CrossRef]

67. Tarwal, N.; Patil, P. Superhydrophobic and transparent ZnO thin films synthesized by spray pyrolysis technique. Appl. Surf. Sci. 2010, 256, 7451-7456. [CrossRef]

68. Azimi, G.; Dhiman, R.; Kwon, H.-M.; Paxson, A.T.; Varanasi, K.K. Hydrophobicity of rare-earth oxide ceramics. Nat. Mater. 2013, 12, 315-320. [CrossRef] [PubMed]

69. Zhao, J.; Li, Z.; Zhang, M.; Meng, A. Super-hydrophobic surfaces of SiO2-coated SiC nanowires: Fabrication, mechanism and ultraviolet-durable super-hydrophobicity. J. Colloid Interface Sci. 2015, 444, 33-37. [CrossRef] [PubMed] 
70. He, G.; Wang, K. The super hydrophobicity of ZnO nanorods fabricated by electrochemical deposition method. Appl. Surf. Sci. 2011, 257, 6590-6594. [CrossRef]

71. Chatterjee, A.; Derby, M.M.; Peles, Y.; Jensen, M.K. Condensation heat transfer on patterned surfaces. Int. J. Heat Mass Transf. 2013, 66, 889-897. [CrossRef]

72. Baojin, Q.; Li, Z.; Hong, X.; Yan, S. Experimental study on condensation heat transfer of steam on vertical titanium plates with different surface energies. Exp. Therm. Fluid Sci. 2011, 35, 211-218. [CrossRef]

73. Kim, H.; Nam, Y. Condensation behaviors and resulting heat transfer performance of nano-engineered copper surfaces. Int. J. Heat Mass Transf. 2016, 93, 286-292. [CrossRef]

74. Miljkovic, N.; Enright, R.; Wang, E.N. Effect of Droplet Morphology on Growth Dynamics and Heat Transfer during Condensation on Superhydrophobic Nanostructured Surfaces. ACS Nano 2012, 6, 1776-1785. [CrossRef]

75. Yin, L.; Wang, Y.; Ding, J.; Wang, Q.; Chen, Q. Water condensation on superhydrophobic aluminum surfaces with different low-surface-energy coatings. Appl. Surf. Sci. 2012, 258, 4063-4068. [CrossRef]

76. Anand, S.; Paxson, A.T.; Dhiman, R.; Smith, J.D.; Varanasi, K.K. Enhanced Condensation on Lubricant-Impregnated Nan-otextured Surfaces. ACS Nano 2012, 6, 10122-10129. [CrossRef] [PubMed]

77. Hu, H.; Niu, D.; Tang, S. Condensation heat transfer performance of heat transfer tubes with diffenrent wettabilities in presence of a larger amount of noncondensable gas. J. Xi'an Jiaotong Univ. 2015, 49, 30-36. (In Chinese)

78. Varanasi, K.K.; Hsu, M.; Bhate, N.; Yang, W.; Deng, T. Spatial control in the heterogeneous nucleation of water. Appl. Phys. Lett. 2009, 95, 094101. [CrossRef]

79. Ma, X.; Du, B.; Hu, S. Effect of contact angle hysteresis on droplet dynamic behaviors for hybrid surface. J. Eng. Thermophys. 2017, 38, 855-861. (In Chinese)

80. Ma, X.; Liu, X.; Luo, S. Experimental Investigation of mix-vapor condensation with hydrophobic-superhydrophobic hybrid surface on inclined tubes. J. Eng. Thermophys. 2018, 39, 860-865. (In Chinese)

81. Peng, B.; Lan, Z.; Xu, W. Experimental Investigation of dropwise condensation of steam on hydrophobic-superhydrophobic hybrid surface. J. Eng. Thermophys. 2014, 35, 2036-2040. (In Chinese)

82. Peng, B.; Ma, X.; Lan, Z. Steam condensation heat transfer enhancement through droplet properties manipulation with hybrid surface. CIESC J. 2015, 66, 3826-3833. (In Chinese)

83. Zhou, D.; Ji, X.; Dai, C. Steam condensation heat transfer enhancement on superhydropbilic-hydropbobic hybrid vertical surface. J. Mech. Eng. 2018, 54, 182-187. (In Chinese) [CrossRef]

84. Varanasi, K.K.; Deng, T. Controlling nucleation and growth of water using hybrid hydrophobic-hydrophilic surfaces. In Proceedings of the 2010 12th Ieee Intersociety Conference on Thermal and Thermomechanical Phenomena in Electronic Systems, Las Vegas, NV, USA, 2-5 June 2010; pp. 1-5.

85. Chen, X.; Wu, J.; Ma, R.; Hua, M.; Koratkar, N.; Yao, S.; Wang, Z. Nanograssed Micropyramidal Architectures for Continu-ous Dropwise Condensation. Adv. Funct. Mater. 2011, 21, 4617-4623. [CrossRef]

86. Hou, Y.; Yu, M.; Chen, X.; Wang, Z.; Yao, S. Recurrent Filmwise and Dropwise Condensation on a Beetle Mimetic Surface. ACS Nano 2015, 9, 71-81. [CrossRef]

87. Cheng, J.; Vandadi, A.; Chen, C.-L. Condensation heat transfer on two-tier superhydrophobic surfaces. Appl. Phys. Lett. 2012, 101, 131909. [CrossRef]

88. Daniel, S.; Chaudhury, M.K.; Chen, J.C. Fast Drop Movements Resulting from the Phase Change on a Gradient Surface. Science 2001, 291, 633-636. [CrossRef]

89. Boreyko, J.B.; Chen, C.-H. Self-Propelled Dropwise Condensate on Superhydrophobic Surfaces. Phys. Rev. Lett. 2009, $103,184501$. [CrossRef]

90. Chu, F.; Wu, X.; Zhu, Y. Theoretical model for multidroplet coalescence induced droplet jumping on superhydrophobic surfaces. J. Mech. Eng. 2017, 38, 352-357. (In Chinese)

91. Li, G.; Alhosani, M.H.; Yuan, S.; Liu, H.; Al Ghaferi, A.; Zhang, T. Microscopic Droplet Formation and Energy Transport Analysis of Condensation on Scalable Superhydrophobic Nanostructured Copper Oxide Surfaces. Langmuir 2014, 30, 14498-14511. [CrossRef] [PubMed]

92. He, M.; Zhang, Q.; Zeng, X.; Cui, D.; Chen, J.; Li, H.; Wang, J.; Song, Y. Hierarchical Porous Surface for Efficiently Control-ling Microdroplets' Self-Removal. Adv. Mater. 2013, 25, 2291-2295. [CrossRef] [PubMed]

93. Miljkovic, N.; Preston, D.J.; Enright, R.; Wang, E.N. Electrostatic charging of jumping droplets. Nat. Commun. 2013, 4, 2517. [CrossRef]

94. Yan, X.; Li, J.; Li, L.; Huang, Z.; Wang, F.; Wei, Y. Droplet condensation on superhydrophobic surfaces with enhanced dewetting under a tangential AC electric field. Appl. Phys. Lett. 2016, 109, 161601. [CrossRef]

95. Zang, D.; Yu, Y.; Chen, Z.; Li, X.; Wu, H.; Geng, X. Acoustic levitation of liquid drops: Dynamics, manipulation and phase transitions. Adv. Colloid Interface Sci. 2017, 243, 77-85. [CrossRef] [PubMed]

96. Boreyko, J.B.; Baker, C.H.; Poley, C.R.; Chen, C.-H. Wetting and Dewetting Transitions on Hierarchical Superhydrophobic Surfaces. Langmuir 2011, 27, 7502-7509. [CrossRef]

97. Boreyko, J.B.; Chen, C.-H. Restoring Superhydrophobicity of Lotus Leaves with Vibration-Induced Dewetting. Phys. Rev. Lett. 2009, 103, 174502. [CrossRef] [PubMed] 